\title{
CMEARTICLE
}

\section{Clinics in diagnostic imaging (183)}

Qi Hui Bernice Heng ${ }^{1}$, MBBS, MRCS, Dinesh $\underline{\text { Chinchure }}^{2}$, MBBS, FRCR, Reyaz Moiz Singaporewalla ${ }^{1}$, FRCSEd, MMed

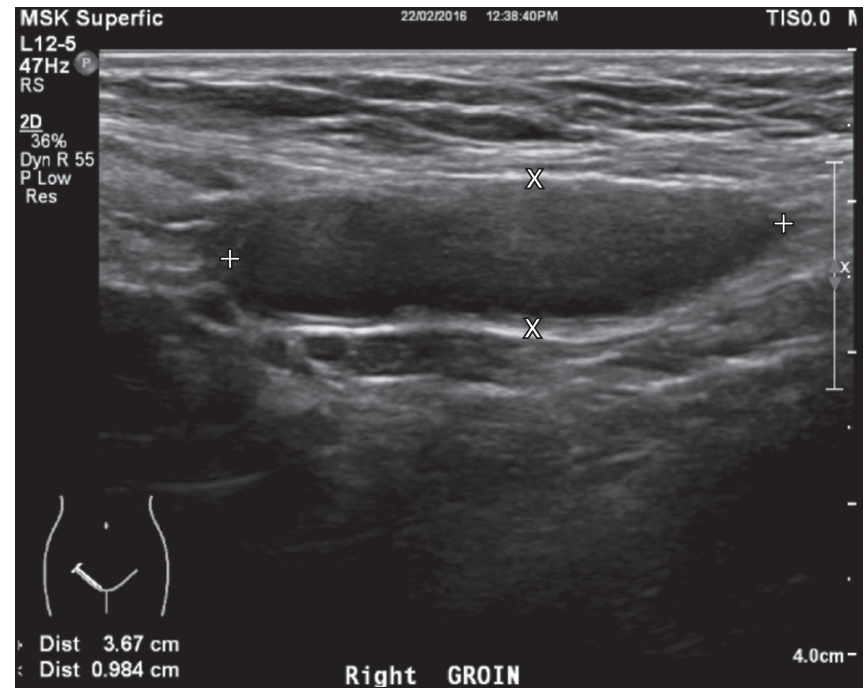

Fig. 1 Longitudinal US image of the right groin.

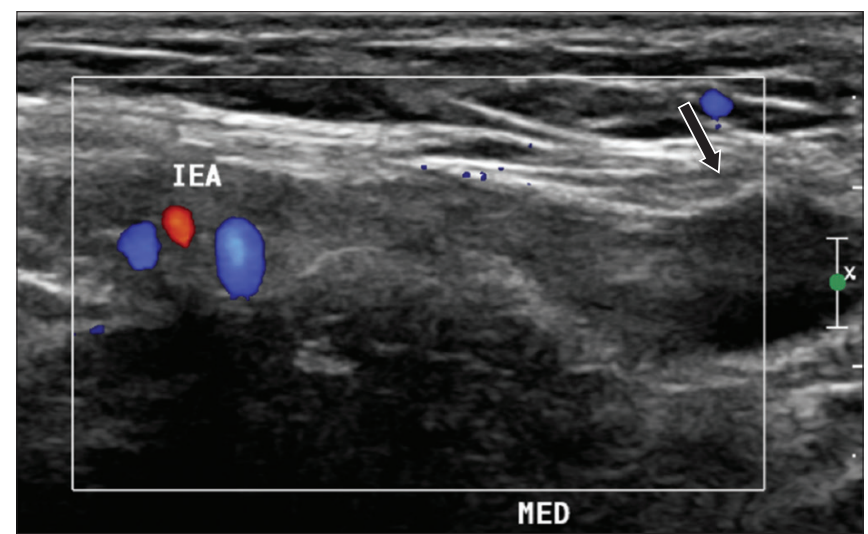

Fig. 2 Colour Doppler US image of the right groin. IEA: inferior epigastric artery; MED: medial

\section{CASE PRESENTATION}

A 31-year-old Chinese woman with no significant medical or surgical history initially presented to the general surgery service with right groin swelling of one month's duration. The swelling became more prominent with exertion and prolonged standing, and was associated with mild discomfort. On palpation, there was a non-tender, soft cystic swelling at the right groin, but no classical expansile cough impulse was present. The swelling was not manually reducible upon lying down.

In view of the above clinical findings, ultrasonography of the right groin was ordered in the outpatient setting (Figs. 1 \& 2). What do these images show? What is the diagnosis? 


\section{IMAGE INTERPRETATION}

Ultrasonography of the right groin shows a well-circumscribed elongated cystic structure in the right inguinal region measuring $3.7 \mathrm{~cm} \times 1.8 \mathrm{~cm} \times 0.9 \mathrm{~cm}$ (Fig. 1). The width and the length of the cystic lesion in the inguinal canal are indicated by the ' $x$ ' and '+' symbols, respectively (Fig. 1). Colour Doppler ultrasonography image of the right groin shows an avascular cystic lesion (arrow, Fig. 2). No significant change in size was demonstrated with the Valsalva manoeuvre. No internal vascularity was noted on colour Doppler examination.

\section{DIAGNOSIS}

Right hydrocoele of the canal of Nuck.

\section{CLINICAL COURSE}

This patient eventually underwent an elective laparoscopic excision of the right hydrocoele of the canal of Nuck. Laparoscopy revealed a right patent processus vaginalis with the round ligament exiting the peritoneal cavity into the canal of Nuck lateral to the inferior epigastric vessels. There were no contents in the canal. The peritoneal sac and round ligament were excised, and the wide, deep inguinal ring defect was reinforced with a mesh in a manner similar to the transabdominal preperitoneal (TAPP) mesh repair technique. The mesh was anchored in place using absorbable tackers, and the peritoneal flap was anchored back in place with absorbable tackers to cover the mesh. The patient recovered well postoperatively.

\section{DISCUSSION}

Hydrocoele of the canal of Nuck is a rare condition in adult women caused by a failure of complete obliteration of the canal of Nuck. We herein report the case of a female patient with a hydrocoele of the canal of Nuck who was diagnosed using ultrasonography and treated with laparoscopic mesh repair. Cystic groin masses in women are rare, and the anatomic and embryologic characteristics of the groin area are complex. Hence, a good understanding of the local anatomic characteristics of the groin allows characterisation of pathologic conditions in the groin. We focus on the female anatomy in this article, as the male inguinal anatomy is well-described.

The inguinal region encompasses two adjacent but anatomically distinct areas: the inguinal canal and the femoral triangle. The inguinal canal is a 4-cm oblique passage that passes inferomedially from the internal to the external inguinal rings, and lies parallel to and immediately above the inguinal ligament. The inguinal canal contains the round ligament (i.e. spermatic cord in the male) and its fascial coverings. The round ligaments are bilateral structures arising from the uterine horns, where the uterus and fallopian tubes meet. They course laterally from the uterus through the broad ligament and extend laterally and anteriorly along the pelvic wall, hooking around the inferior epigastric artery before leaving the abdomen through the deep inguinal ring. The round ligament traverses the inguinal canal with the round ligament artery and ilioinguinal nerve, and terminates in the labia majora. ${ }^{(1-2)}$ The round ligament consists mainly of muscular tissue derived from the uterus, fibrous and areolar tissue, and blood vessel and nerves. These are enclosed in a double fold of peritoneum which, in the fetus, is a tubular process extending for a short distance into the inguinal canal, called the canal of Nuck. It is generally obliterated in adults but sometimes remains patent even into adulthood, as in this patient's case.

Hydrocoele of the canal of Nuck in the adult woman may be likened to a patent processus vaginalis in men. The processus vaginalis is an evagination of parietal peritoneum that occurs before the descent of the testes. In women, the same evagination accompanies the round ligament of the uterus as it descends into the labia majora through the inguinal canal. The canal of Nuck is usually obliterated at around the eighth month of fetal life. ${ }^{(3-4)}$ Hydrocoeles of the canal of Nuck typically present as an irreducible, painless swelling in the inguinolabial region that is sometimes transilluminable. ${ }^{(5)}$ They can also present as a painful lump and cause an erythematous swelling extending to the labia majora in rare cases of infection. ${ }^{(3)}$ However, the diagnosis of a hydrocoele in women is seldom made on clinical examination alone. In one-third of patients, a concomitant inguinal hernia is found. ${ }^{(4-6)}$ Therefore, imaging is crucial in making a diagnosis for groin lumps.

The use of ultrasonography supported by colour Doppler imaging has increased in recent years due to its advantage as a noninvasive and dynamic assessment of soft tissues, which is difficult to achieve with other imaging modalities. In this patient, ultrasonography showed a well-circumscribed, elongated cystic structure in the right inguinal region with no internal vascularity noted on colour Doppler examination. It is prudent for clinicians to consider other diagnoses of cystic lesions in the inguinal region on ultrasonography.

Although not harmful, a canal of Nuck cyst can cause discomfort and pain. The symptoms are usually more pronounced on prolonged standing. As in our patient's case, clinical history showed that the groin swelling slowly disappeared at night when the patient was lying down and reappeared gradually during the day when the patient was ambulating, ruling out the diagnosis of a mesothelial cyst. This characteristic was more suggestive of a groin hernia. Furthermore, this swelling did not have the classical expansile cough impulse associated with inguinal hernias and also could not be manually reduced. Cystic consistency coupled with the above symptoms and signs should remind clinicians to include this condition in their differential diagnosis when encountering groin lumps in women. In our case, it led to ultrasonography of the groin to further ascertain the nature and contents of the groin swelling. Ho et al have mentioned some rare instances of abnormal pathology involving the canal of Nuck, including endometriosis, infection and neoplasm. However, most cases are benign. ${ }^{(7)}$

There are a few conditions that can be confused with hydrocoele of the canal of Nuck on sonography. Oh et al described a cystic groin mass in a woman as rare and highlighted seven masses they encountered in their patients. Interestingly, a cyst of the canal of Nuck was not mentioned, likely due to its comparative rarity. ${ }^{(2)}$ Sonographic features of groin masses were also discussed by Shadbolt et al. ${ }^{(8)}$ Their paper also described 
Table I. Sonographic and clinical features of cystic groin masses in women.

\begin{tabular}{|c|c|c|}
\hline $\begin{array}{l}\text { Differential } \\
\text { diagnosis }\end{array}$ & Sonographic characteristics & Clinical features \\
\hline $\begin{array}{l}\text { Inguinal/femoral } \\
\text { hernia }\end{array}$ & $\begin{array}{l}\text { - Direct visualisation of bowel loop peristalsis or fat } \\
\text { entering the hernia sac on straining } \\
\text { - 'To and fro' motion of peritoneal fluid within the } \\
\text { hernia } \\
\text { - Echogenic omental fat }\end{array}$ & $\begin{array}{l}\text { - Inguinal hernias are most common } \\
\text { - Features: positive expansile cough impulse; } \\
\text { located superior and medial to the pubic tubercle; } \\
\text { often reduces spontaneously on lying down or by } \\
\text { manipulation (in large hernias) } \\
\text { - Femoral hernia lies within the femoral canal. } \\
\text { The hernia sac is below and lateral to the pubic } \\
\text { tubercle; almost always incarcerated due to } \\
\text { its narrow canal neck and does not reduce on } \\
\text { manipulation }\end{array}$ \\
\hline Abscesses & $\begin{array}{l}\text { - Anechoic or hypoechoic } \\
\text { - Occasionally with debris or septation }\end{array}$ & $\begin{array}{l}\text { - Tuberculous abscesses can develop in the groin } \\
\text { area } \\
\text { - Large iliopsoas abscesses can extend to the groin } \\
\text { with destruction of the pubic bone } \\
\text { - Ultrasonography may be used to direct } \\
\text { percutaneous aspiration biopsy } \\
\text { - Features: tender fluctuant mass; erythematous; } \\
\text { warm }\end{array}$ \\
\hline Epidermal cysts & $\begin{array}{l}\text { Well-defined hypoechoic mass with variable internal } \\
\text { echoes in the subcutaneous layer }\end{array}$ & $\begin{array}{l}\text { - Commonly located on the scalp, face, neck, trunk } \\
\text { and back, including the groin } \\
\text { - Features: firm, well-circumscribed lump, attached } \\
\text { to the skin; may be a punctum }\end{array}$ \\
\hline Pseudoaneurysms & $\begin{array}{l}\text { - Sonography with Doppler imaging is crucial in the } \\
\text { diagnosis } \\
\text { - The anechoic cavity of the pseudoaneurysm } \\
\text { communicates with the femoral artery with a } \\
\text { turbulent vascular flow }\end{array}$ & $\begin{array}{l}\text { - The incidence of an iatrogenic pseudoaneurysm is } \\
\text { more common in women than in men } \\
\text { - Feature: pulsatile mass after catheterisation of the } \\
\text { femoral artery }\end{array}$ \\
\hline $\begin{array}{l}\text { Varicosities (varices) } \\
\text { of the round ligament }\end{array}$ & $\begin{array}{l}\text { - Prominent venous plexus with accompanying } \\
\text { dilated draining veins and a typical 'bag of worms' } \\
\text { appearance of smaller veins } \\
\text { - Change in shape of the cystic masses with position, } \\
\text { as well as with the Valsalva manoeuvre }\end{array}$ & $\begin{array}{l}\text { In pregnancy, commonly secondary to: }{ }^{(11)} \\
\text { - Progesterone-mediated smooth muscle relaxation } \\
\text { - Increased cardiac output } \\
\text { - Pelvic venous obstruction by the gravid uterus }\end{array}$ \\
\hline $\begin{array}{l}\text { Cystic } \\
\text { lymphangiomas }\end{array}$ & $\begin{array}{l}\text { - Multilocular cystic mass without vascular flow } \\
\text { - Insinuating pattern between the vascular structures } \\
\text { - No stalk-like structure (as compared to mesothelial } \\
\text { cysts) }\end{array}$ & $\begin{array}{l}\text { - Uncommon congenital lymphatic hamartomas } \\
\text { - Benign; } 95 \% \text { in the neck and axilla, less commonly } \\
\text { in the retroperitoneum and groin } \\
\text { - Features: soft, painless, compressible (doughy) } \\
\text { mass that usually transilluminates }\end{array}$ \\
\hline $\begin{array}{l}\text { Mesothelial cysts of } \\
\text { the round ligament }\end{array}$ & $\begin{array}{l}\text { Fusiform-shaped cystic mass without peristalsis, } \\
\text { connected to a stalk-like structure }\end{array}$ & $\begin{array}{l}\text { - Commonly in the right groin of middle-aged women } \\
\text { - No variation in size with movement }\end{array}$ \\
\hline $\begin{array}{l}\text { Herniation of the } \\
\text { ovary }\end{array}$ & $\begin{array}{l}\text { Findings vary according to the cystic components of } \\
\text { the ovary }\end{array}$ & $\begin{array}{l}\text { - Usually occurs in infants/girls, very rare in adults } \\
\text { - } 31 \% \text { of inguinal hernia sacs in female infants } \\
\text { contain uterine adnexa; however, this decreases } \\
\text { with age }\end{array}$ \\
\hline $\begin{array}{l}\text { Hydrocoele of the } \\
\text { canal of Nuck }\end{array}$ & $\begin{array}{l}\text { - Sausage-shaped }{ }^{(12)} \\
\text { - Extending along the route of the round ligament } \\
\text { - Communication with the peritoneal cavity is not } \\
\text { demonstrable }{ }^{(8)} \\
\text { - No change with the Valsalva manoeuvre }\end{array}$ & $\begin{array}{l}\text { - The canal of Nuck is usually obliterated at around } \\
\text { the eighth month of fetal life }(3-4) \\
\text { - Irreducible painless swelling in the inguinolabial } \\
\text { region } \\
\text { - Classical history of lump disappearing when the } \\
\text { patient wakes up after sleep and slowly reappearing } \\
\text { over time when the patient remains in an upright } \\
\text { position for a long time }\end{array}$ \\
\hline
\end{tabular}

radiological features of various groin masses on computed tomography and magnetic resonance imaging, which is not covered in the scope of this paper. Table I summarises the various sonographic features of cystic groin masses in women, including the sonographic features of the canal of Nuck, and the clinical features of their differential diagnosis. ${ }^{(9)}$

Traditionally, canal of Nuck cysts have been repaired through an open approach. ${ }^{(7)}$ Very few published reports describe entirely laparoscopic management of canal of Nuck cysts. ${ }^{(10)}$ As our patient was symptomatic, we offered diagnostic laparoscopy to confirm the radiological suspicion and to excise the canal of Nuck hydrocoele, followed by reinforcement of the inguinal canal with a mesh. Surgical treatment of canal of Nuck hydrocoeles, whether open or laparoscopic, involves excising the peritoneal hydrocoele sac entering the inguinal canal. Postexcision, the widened deep inguinal ring remains a potential 
site for future inguinal hernia formation. Hence, most surgeons repair and reinforce the inguinal canal. In open surgery, this can be performed using herniorrhaphy or hernioplasty technique. In laparoscopic repair, mesh reinforcement is the usual mode of covering the inguinal canal. Between the totally extraperitoneal (TEP) and TAPP repair laparoscopic approaches, we feel that the TAPP approach is a much better technique, as it allows proper visualisation of the anatomy and confirmation of the clinical diagnosis, for which entry to the peritoneal cavity is essential. Moreover, excising the hydrocoele sac invariably requires division of the peritoneum. In the TEP technique, this would invariably result in loss of the operative field due to escape of air into the peritoneal cavity, making further visualisation and mesh placement challenging.

In conclusion, there are various cystic masses, including those arising from the round ligament in the female groin, that can be differentiated by ultrasonography supported by colour Doppler imaging. Understanding the anatomy and embryology of the inguinal region improves the efficiency of the localisation and characterisation of masses in this area with imaging modalities.

\section{REFERENCES}

1. Gui B, Valentini AL, Ninivaggi V, et al. Deep pelvic endometriosis: don't forget round ligaments. Review of anatomy, clinical characteristics, and MR imaging features. Abdom Imaging 2014; 39:622-32.

2. Oh SN, Jung SE, Rha SE, et al. Sonography of various cystic masses of the female groin. J Ultrasound Med 2007; 26:1735-42.

3. Mandhan P, Raouf Z, Bhatti K. Infected hydrocele of the canal of nuck. Case Rep Urol 2013; 2013:275257.

4. De Meulder F, Wojciechowski M, Hubens G, Ramet J. Female hydrocele of the canal of Nuck: a case report. Eur J Pediatr 2006; 165:193-4.

5. Stickel WH, Manner M. Female hydrocele (cyst of the canal of Nuck): sonographic appearance of a rare and little-known disorder. J Ultrasound Med 2004; 23:429-32.

6. Choi YM, Lee RM, Yi JB, et al. Two cases of female hydrocele of the canal of nuck. Korean J Pediatr 2012; 55:143-6.

7. Ho J, Maa J, Liou P, Lager J. Laparoscopic management of a canal of Nuck cyst. CRSLS 2014; 2134

8. Shadbolt $\mathrm{CL}$, Heinze SB, Dietrich RB. Imaging of groin masses: inguinal anatomy and pathologic conditions revisited. Radiographics 2001; 21 Spec No: S261-71.

9. Anderson CC, Broadie TA, Mackey JE, Kopecky KK. Hydrocele of the canal of Nuck: ultrasound appearance. Am Surg 1995; 61:959-61.

10. Bunting D, Szczebiot L, Cota A. Laparoscopic hernia repair--when is a hernia not a hernia? JSLS 2013; 17:654-6.

11. Lee DK, Bae SW, Moon H, Kim YK. Round ligament varicosities mimicking inguinal hernia in pregnancy. J Korean Surg Soc 2011; 80:437-9.

12. Park SJ, Lee HK, Hong HS, et al. Hydrocele of the canal of Nuck in a girl: ultrasound and MR appearance. Br J Radiol 2004; 77:243-4.
ABSTRACT Hydrocoele of the canal of Nuck is a rare condition in adult women caused by a failure of complete obliteration of the canal of Nuck. It may be likened to a patent processus vaginalis in men. In most cases, the diagnosis is made during surgery as it is often mistaken for an inguinal hernia. We report a case where the diagnosis of this condition was made preoperatively on imaging. The salient anatomy, clinical features, radiological images and surgical management are discussed and the medical literature reviewed.

Keywords: canal of Nuck, female, hydrocoele, imaging, management 


\section{SINGAPORE MEDICAL COUNCIL CATEGORY 3B CME PROGRAMME} (Code SMJ 201801A)

Question 1. Regarding the canal of Nuck:

(a) Hydrocoele of the canal of Nuck can be likened to a patent processus vaginalis in men.

(b) It is an evagination of the visceral peritoneum.

(c) It is usually obliterated at around the eighth month of fetal life.

(d) It accompanies the round ligament of the uterus in women.

Question 2. Regarding the clinical features of hydrocoele of the canal of Nuck:

(a) Clinical history helps in making a diagnosis.

(b) It has an expansile cough impulse.

(c) It presents as an irreducible cystic groin lump.

(d) Infected hydrocoeles may present as a painful, erythematous lump extending to the labia majora.

Question 3. On Doppler ultrasonography, a hydrocoele of the canal of Nuck shows:

(a) Internal vascularity on colour Doppler.

(b) A well-circumscribed cystic lesion.

(c) Changes with the Valsalva manoeuvre.

(d) Communication with the peritoneal cavity.

Question 4. The differential diagnosis of a hydrocoele of the canal of Nuck includes:
(a) Inguinal lymphadenopathy.
(b) Groin hernia.
(c) Saphena varix.
(d) Mesothelial cyst of the round ligament.

Question 5. Regarding treatment options of a hydrocoele of the canal of Nuck:
(a) Open or laparoscopic surgery may be performed.
(b) Mesh repair may be required to prevent postoperative inguinal hernia.
(c) Percutaneous aspiration of fluid is adequate treatment.
(d) The round ligament needs to be excised with the hydrocoele sac during the surgery.

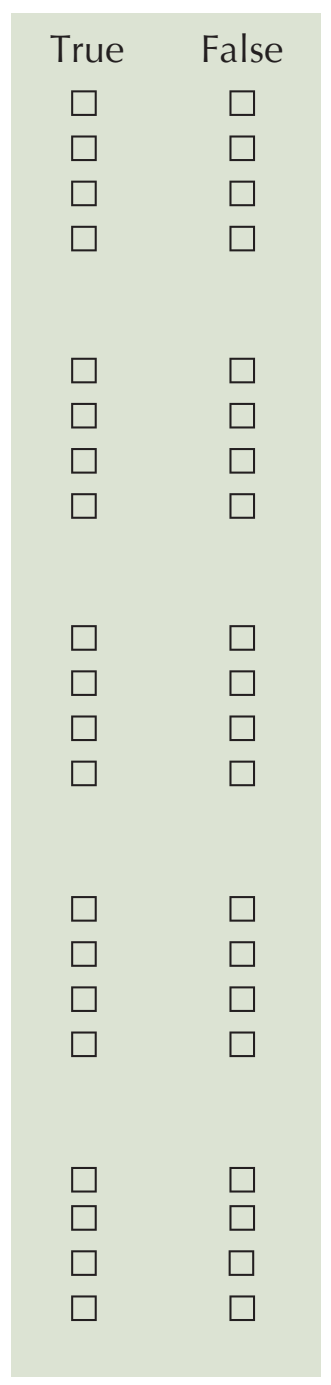

\section{Doctor's particulars:}

Name in full:

MCR no:

Specialty:

Email:

\section{SUBMISSION INSTRUCTIONS:}

Visit the SMJ website: http://www.smj.org.sg/current-issue and select the appropriate quiz. You will be redirected to the SMA login page.

For SMA member: (1) Log in with your username and password (if you do not know your password, please click on 'Forgot your password?'). (2) Select your answers for each quiz and click 'Submit'.

For non-SMA member: (1) Create an SMJ CME account, or log in with your SMJ CME username and password (for returning users). (2) Make payment of SGD 21.40 (inclusive of $7 \%$ GST) via PayPal to access this month's quizzes. (3) Select your answers for each quiz and click 'Submit'.

RESULTS:

(1) Answers will be published online in the SMJ March 2018 issue. (2) The MCR numbers of successful candidates will be posted online at the SMJ website by 8 March 2018. (3) Passing mark is $60 \%$. No mark will be deducted for incorrect answers. (4) The SMJ editorial office will submit the list of successful candidates to the Singapore Medical Council. (5) One CME point is awarded for successful candidates.

Deadline for submission: (January 2018 SMJ 3B CME programme): 12 noon, 1 March 2018 